\title{
The ALMA-PILS survey: Stringent limits on small amines and nitrogen-oxides towards IRAS 16293-2422B
}

\author{
N. F. W. Ligterink ${ }^{1,2}$, H. Calcutt ${ }^{3}$, A. Coutens ${ }^{4}$, L. E. Kristensen ${ }^{3}$, T. L. Bourke ${ }^{5}$, M. N. Drozdovskaya ${ }^{6}$, \\ H. S. P. Müller ${ }^{7}$, S. F. Wampfler ${ }^{6}$, M. H. D. van der Wiel ${ }^{8}$, E. F. van Dishoeck ${ }^{2,9}$, and J. K. Jørgensen ${ }^{3}$ \\ ${ }^{1}$ Raymond and Beverly Sackler Laboratory for Astrophysics, Leiden Observatory, Leiden University, PO Box 9513, 2300 RA Leiden, \\ The Netherlands \\ ${ }^{2}$ Leiden Observatory, Leiden University, PO Box 9513, 2300 RA Leiden, The Netherlands \\ e-mail: ligterink@strw.leidenuniv.nl \\ ${ }^{3}$ Centre for Star and Planet Formation, Niels Bohr Institute \& Natural History Museum of Denmark, University of Copenhagen, \\ Øster Voldgade 5-7, 1350 Copenhagen, Denmark \\ ${ }^{4}$ Laboratoire d'Astrophysique de Bordeaux, Université de Bordeaux, CNRS, B18N, allée Geoffroy Saint-Hilaire, 33615 Pessac, \\ France \\ ${ }^{5}$ SKA Organization, Jodrell Bank Observatory, Lower Withington, Macclesfield, Cheshire SK11 9DL, UK \\ ${ }^{6}$ Center for Space and Habitability (CSH), University of Bern, Sidlerstrasse 5, 3012 Bern, Switzerland \\ ${ }^{7}$ I. Physikalisches Institut, Universität zu Köln, Zülpicher Str. 77, 50937 Köln, Germany \\ 8 ASTRON, The Netherlands Institute for Radio Astronomy, Postbus 2, 7990 AA Dwingeloo, The Netherlands \\ ${ }^{9}$ Max-Planck Institut für Extraterrestrische Physik (MPE), Giessenbachstr. 1, 85748 Garching, Germany
}

Received 22 September 2017 / Accepted 31 July 2018

\begin{abstract}
Context. Hydroxylamine $\left(\mathrm{NH}_{2} \mathrm{OH}\right)$ and methylamine $\left(\mathrm{CH}_{3} \mathrm{NH}_{2}\right)$ have both been suggested as precursors to the formation of amino acids and are therefore, of interest to prebiotic chemistry. Their presence in interstellar space and formation mechanisms, however, are not well established.

Aims. We aim to detect both amines and their potential precursor molecules $\mathrm{NO}, \mathrm{N}_{2} \mathrm{O}$, and $\mathrm{CH}_{2} \mathrm{NH}$ towards the low-mass protostellar binary IRAS 16293-2422, in order to investigate their presence and constrain their interstellar formation mechanisms around a young Sun-like protostar.

Methods. ALMA observations from the unbiased, high-angular resolution and sensitivity Protostellar Interferometric Line Survey (PILS) are used. Spectral transitions of the molecules under investigation are searched for with the CASSIS line analysis software.

Results. $\mathrm{CH}_{2} \mathrm{NH}$ and $\mathrm{N}_{2} \mathrm{O}$ are detected for the first time, towards a low-mass source, the latter molecule through confirmation with the single-dish TIMASSS survey. $\mathrm{NO}$ is also detected. $\mathrm{CH}_{3} \mathrm{NH}_{2}$ and $\mathrm{NH}_{2} \mathrm{OH}$ are not detected and stringent upper limit column densities are determined.

Conclusions. The non-detection of $\mathrm{CH}_{3} \mathrm{NH}_{2}$ and $\mathrm{NH}_{2} \mathrm{OH}$ limits the importance of formation routes to amino acids involving these species. The detection of $\mathrm{CH}_{2} \mathrm{NH}$ makes amino acid formation routes starting from this molecule plausible. The low abundances of $\mathrm{CH}_{2} \mathrm{NH}$ and $\mathrm{CH}_{3} \mathrm{NH}_{2}$ compared to Sgr B2 indicate that different physical conditions influence their formation in low- and high-mass sources.
\end{abstract}

Key words. astrochemistry - stars: formation - stars: protostars - ISM: molecules - ISM: individual objects: IRAS 16293-2422 astrobiology

\section{Introduction}

The small molecules methylamine $\left(\mathrm{CH}_{3} \mathrm{NH}_{2}\right)$ and hydroxylamine $\left(\mathrm{NH}_{2} \mathrm{OH}\right)$ with an amine $\left(-\mathrm{NH}_{2}\right)$ functional group have both been suggested as precursors to the formation of amino acids (Blagojevic et al. 2003; Holtom et al. 2005; Snow et al. 2007; Bossa et al. 2009; Barrientos et al. 2012; Garrod 2013). Reactions involving these molecules could explain the presence of simplest amino acid glycine in comets (Elsila et al. 2009; Altwegg et al. 2016). Despite their importance, both $\mathrm{CH}_{3} \mathrm{NH}_{2}$ and $\mathrm{NH}_{2} \mathrm{OH}$ have turned out to be quite elusive molecules in the interstellar medium. $\mathrm{CH}_{3} \mathrm{NH}_{2}$ has exclusively been detected towards Sgr B2 and tentatively to Orion KL (e.g., Kaifu et al. 1974; Pagani et al. 2017). Upper limit abundances of $\mathrm{CH}_{3} \mathrm{NH}_{2}$ towards other high-mass sources are generally found to be consistent with values determined towards Sgr B2 (Ligterink et al. 2015). In the solar system, $\mathrm{CH}_{3} \mathrm{NH}_{2}$ has been detected in comets 81P/Wild 2 and 67P/Churyumov-Gerasimenko (hereafter 67P/C-G; Elsila et al. 2009; Goesmann et al. 2015; Altwegg et al. 2017). $\mathrm{NH}_{2} \mathrm{OH}$ has not been detected thus far, down to upper limit abundances of $\sim 10^{-11}$ with respect to $\mathrm{H}_{2}$ (Pulliam et al. 2012; McGuire et al. 2015).

The lack of detection of these two molecules not only constrains amino acid formation, but also contrasts with model predictions. Garrod et al. (2008) predicted efficient $\mathrm{CH}_{3} \mathrm{NH}_{2}$ formation from the radical addition reaction $\mathrm{CH}_{3}+\mathrm{NH}_{2}$ in their models, whereas $\mathrm{NH}_{2} \mathrm{OH}$ is assumed to form from the $\mathrm{NH}+\mathrm{OH}$ addition followed by hydrogenation and $\mathrm{NH}_{2}+\mathrm{OH}$ reactions on ice surfaces. Abundances of $\mathrm{CH}_{3} \mathrm{NH}_{2}$ and $\mathrm{NH}_{2} \mathrm{OH}$ are predicted to be on the order of $10^{-6}-10^{-7}$, depending on the model. It is generally found that these models overproduce both molecules compared with observations (Pulliam et al. 2012; 
Ligterink et al. 2015). Therefore, other formation, reaction or destruction mechanisms need to be considered.

Several laboratory experiments have investigated the formation of $\mathrm{NH}_{2} \mathrm{OH}$ and $\mathrm{CH}_{3} \mathrm{NH}_{2}$. Zheng \& Kaiser (2010) show the formation of $\mathrm{NH}_{2} \mathrm{OH}$ from electron irradiated $\mathrm{H}_{2} \mathrm{O}: \mathrm{NH}_{3}$ ice mixtures, while $\mathrm{He}$ et al. (2015) produce the molecule by oxidation of $\mathrm{NH}_{3}$ ice. Alternatively, $\mathrm{NH}_{2} \mathrm{OH}$ is seen to efficiently form from the solid-state hydrogenation of nitric oxide (NO; Congiu et al. 2012; Fedoseev et al. 2012). In this scenario, NO is accreted from the gas-phase onto dust grains during cloud collapse (Visser et al. 2011). Nitrous oxide $\left(\mathrm{N}_{2} \mathrm{O}\right)$ is found as a by-product of NO hydrogenation reactions. NO has been observed in a variety of sources (e.g., Liszt \& Turner 1978; Y1ld1z et al. 2013; Codella et al. 2018). It is thought to mainly form via the $\mathrm{N}+\mathrm{OH} \rightarrow \mathrm{NO}+\mathrm{H}$ neutral-neutral reaction in the gas-phase. Observations suggest that $\mathrm{N}_{2} \mathrm{O}$ is related to $\mathrm{NO}$ (Ziurys et al. 1994; Halfen et al. 2001).

$\mathrm{CH}_{3} \mathrm{NH}_{2}$ formation has been demonstrated in electron irradiated $\mathrm{CH}_{4}: \mathrm{NH}_{3}$ ice mixtures (Kim \& Kaiser 2011; Förstel et al. 2017), with the main formation pathways suggested to proceed through $\mathrm{CH}_{3}+\mathrm{NH}_{2}$ radical reactions. Theule et al. (2011) investigated hydrogenation of solid hydrogen cyanide $(\mathrm{HCN})$ and methanimine $\left(\mathrm{CH}_{2} \mathrm{NH}\right)$, both of which lead to $\mathrm{CH}_{3} \mathrm{NH}_{2}$ formation. $\mathrm{CH}_{2} \mathrm{NH}$ is hypothesized to have a larger reaction probability than $\mathrm{HCN}$ and reaction-pathways to $\mathrm{CH}_{3} \mathrm{NH}_{2}$ may be completely different for reactions starting from either $\mathrm{HCN}$ or $\mathrm{CH}_{2} \mathrm{NH}$. In contrast with $\mathrm{CH}_{3} \mathrm{NH}_{2}$, its potential precursor $\mathrm{CH}_{2} \mathrm{NH}$ has been observed in numerous sources (Dickens et al. 1997; Nummelin et al. 2000; Belloche et al. 2013; Suzuki et al. 2016). Halfen et al. (2013) investigated the relationship between this molecule and $\mathrm{CH}_{3} \mathrm{NH}_{2}$ in Sgr B2 and concluded that the two species have different formation routes, due to observed differences in rotational temperature and distribution. Interestingly, $\mathrm{CH}_{2} \mathrm{NH}$ has also been implied as a precursor to amino acid formation (e.g., Woon 2002; Danger et al. 2011).

Searches for $\mathrm{CH}_{3} \mathrm{NH}_{2}$ and $\mathrm{NH}_{2} \mathrm{OH}$ have so far mainly focused on high-mass sources. Detections or upper limits of these two molecules and their potential precursors towards a low-mass source would therefore, expand our understanding of amine-containing molecules and their formation in the ISM. The low-mass solar-type protostellar binary IRAS 16293-2422 (hereafter IRAS 16293) is an ideal source for such a study. Its physics and chemistry are well studied and it is abundant in complex organic molecules (e.g., Jørgensen et al. 2016). Abundance ratios will therefore, constrain the chemistry of $-\mathrm{NH}_{2}$ molecules as has been done for other nitrogen-bearing species (Coutens et al. 2016; Ligterink et al. 2017). In this paper, we present the first detection of $\mathrm{CH}_{2} \mathrm{NH}$ and $\mathrm{N}_{2} \mathrm{O}$ towards a low-mass protostar. NO is also detected and analysed. The abundances of $\mathrm{NH}_{2} \mathrm{OH}$ and $\mathrm{CH}_{3} \mathrm{NH}_{2}$ are constrained by upper limits from non-detections.

\section{Observations and data analysis}

The observations were taken as part of the Protostellar Interferometric Line Survey (PILS), an unbiased-spectral survey using the Atacama Large Millimeter Array (ALMA; Jørgensen et al. 2016). The survey covers a spectral range of 329.147-362.896 GHz in Band 7, obtained with the $12 \mathrm{~m}$ array and the Atacama Compact Array (ACA). The combined data set analysed in this work was produced with a circular restoring beam of 0.5 . The maximum recoverable scale is $13^{\prime \prime}$. A spectral resolution of $0.2 \mathrm{~km} \mathrm{~s}^{-1}$ and a root mean square (RMS) noise level of about $7-10 \mathrm{mJy} \mathrm{beam}^{-1}$ channel $^{-1}$, i.e., approximately
4-5 mJy beam ${ }^{-1} \mathrm{~km} \mathrm{~s}^{-1}$ is obtained. The dataset has a calibration uncertainty of $5-10 \%$.

The spectral analysis presented below is performed towards source B in IRAS 16293 at a position offset by one beam diameter $\left(0{ }^{\prime} 5\right)$ from the continuum peak position in the south-west direction $\left(\alpha_{J 2000}=16^{\mathrm{h}} 32^{\mathrm{m}} 22^{\mathrm{s}} .58, \delta_{J 2000}=-24^{\circ} 28^{\prime} 32.8^{\prime \prime}\right)$. This position is used for most other PILS molecular identifications and abundance analyses (Coutens et al. 2016; Lykke et al. 2017; Persson et al. 2018). Lines are particularly narrow towards this position, only $1 \mathrm{~km} \mathrm{~s}^{-1}$, limiting line confusion.

The spectra are analysed with the CASSIS software ${ }^{1}$ and linelists from the Jet Propulsion Laboratory ( $\mathrm{JPL}^{2}$ ) catalog for molecular spectroscopy (Pickett et al. 1998) and Cologne Database for Molecular Spectroscopy (CDMS; Müller et al. 2001, 2005). Specifically rotational spectroscopic data of NO, $\mathrm{N}_{2} \mathrm{O}, \mathrm{CH}_{2} \mathrm{NH}, \mathrm{NH}_{2} \mathrm{OH}$, and $\mathrm{CH}_{3} \mathrm{NH}_{2}$ are used (Kirchhoff et al. 1973; Pickett et al. 1979; Morino et al. 2000; Ilyushin et al. 2005; Ting et al. 2014). Identified transitions are fitted with synthetic spectra, assuming Local Thermodynamic Equilibrium (LTE). The input for these fits is given by the column density $(N)$, excitation temperature $\left(T_{\mathrm{ex}}\right)$, line width $\left(F W H M=1 \mathrm{~km} \mathrm{~s}^{-1}\right)$, peak velocity $\left(V_{\text {peak }}\right)$, and a source size of 0.5 , based on the observed spatial extent of the emission. CASSIS software takes beam dilution into account by $\theta_{\text {source }}^{2} /\left(\theta_{\text {source }}^{2}+\theta_{\text {beam }}^{2}\right)$.

Warm, dense dust is present around IRAS 16293B and its emission is coupled to the molecular line emission. This affects the line strength of molecular emission and needs to be corrected by taking a higher background temperature into account, see Eq. (1) for the line brightness $T_{\mathrm{B}}(v)$.

$T_{\mathrm{B}}(v)=T_{0}\left(\frac{1}{e^{T_{0} / T_{\mathrm{ex}}}-1}-\frac{1}{e^{T_{0} / T_{\mathrm{bg}}}-1}\right)\left(1-e^{-\tau \nu}\right)$,

where $T_{0}=h v / k_{\mathrm{B}}$, with $h$ being the Planck constant and $k_{\mathrm{B}}$ the Boltzmann constant. For the one beam offset position at source $B$ $T_{\text {bg }}=21 \mathrm{~K}$, compared to the usual cosmic microwave background temperature of $T_{\mathrm{bg}}=2.7 \mathrm{~K}$.

To compute the best-fit spectral models for each molecule, a grid of models is run to determine the best fitting synthetic spectra. For $\mathrm{CH}_{2} \mathrm{NH}, N$ was varied between $1 \times 10^{14}$ and $5 \times 10^{15} \mathrm{~cm}^{-2}$ and $T_{\text {ex }}$ between 25 and $300 \mathrm{~K}$, while for NO and $\mathrm{N}_{2} \mathrm{O}$ the parameter space of $N=1 \times 10^{15}-1 \times 10^{17} \mathrm{~cm}^{-2}$ and $T_{\mathrm{ex}}=25-400 \mathrm{~K}$ was explored. The $V_{\text {peak }}$ parameter space is explored between 2.5 and $2.9 \mathrm{~km} \mathrm{~s}^{-1}$ and the line $F W H M$ is fixed to $1 \mathrm{~km} \mathrm{~s}^{-1}$, as found for most transitions at this position in the PILS data set (Jørgensen et al. 2016). From this model grid, we obtain the best-fit model solutions through $\chi^{2}$ minimisation. Generally, we accept fits that are within the observational uncertainty of the observed line profile as judged by eye.

The uncertainty in the data, derives from the calibration error $(10 \%)$ and the RMS noise $\left(\mathrm{mJy}\right.$ beam ${ }^{-1}$ channel $\left.^{-1}\right)$ as $\sqrt{\left(0.1 T_{\text {peak }}\right)^{2}+(R M S)^{2}}$, with $T_{\text {peak }}$ the peak brightness of a line. This uncertainty also applies to any best-fit synthetic model. In Table A.1, model parameters for each detected transition, as well as their errors are given. The error on the peak velocity equals the channel width of the observations. The FWHM is kept as a fixed parameter. The error on the peak brightness temperature $\left(T_{\text {peak }}\right)$ is determined from the combination of the RMS and the calibration error of the data, as mentioned above. The largest source of error on the column density and excitation temperature comes from the quality of the fit of spectral model to the data,

\footnotetext{
http://cassis.irap.omp.eu/

2 http://spec.jpl.nasa.gov
} 
Table 1. Column densities and rotational temperatures at the one beam offset position around source B from the ALMA-PILS data.

\begin{tabular}{llccc}
\hline \hline Molecule & Chemical formula & $N_{\text {tot }}^{\dagger}\left(\mathrm{cm}^{-2}\right)$ & $T_{\text {ex }}(\mathrm{K})$ & $V_{\text {peak }}\left(\mathrm{km} \mathrm{s}^{-1}\right)$ \\
\hline Nitric oxide & $\mathrm{NO}$ & $(1.5-2.5) \times 10^{16}$ & $40-150$ & $2.5 \pm 0.2$ \\
Nitrous oxide & $\mathrm{N}_{2} \mathrm{O}$ & $\geq 4.0 \times 10^{16,}$ & $25-350$ & $2.5 \pm 0.2$ \\
Hydroxylamine & $\mathrm{NH}_{2} \mathrm{OH}$ & $\leq 3.7 \times 10^{14}$ & 100 & 2.7 \\
Methanimine & $\mathrm{CH}_{2} \mathrm{NH}$ & $(6.0-10.0) \times 10^{14}$ & $70-120$ & $2.7 \pm 0.2$ \\
Methylamine & $\mathrm{CH}_{3} \mathrm{NH}_{2}$ & $\leq 5.3 \times 10^{14}$ & 100 & 2.7 \\
\hline
\end{tabular}

Notes. All models assume LTE, a $F W H M$ of $1 \mathrm{~km} \mathrm{~s}^{-1}$ and a source size of $0 .{ }^{\prime} 5$. ${ }^{\dagger}$ Upper limits are $3 \sigma$ and determined for $T_{\mathrm{ex}}=100 \mathrm{~K}$. ${ }^{\ddagger}$ Due to the large uncertainty on the highest excitation temperature only the lower limit column density is given.
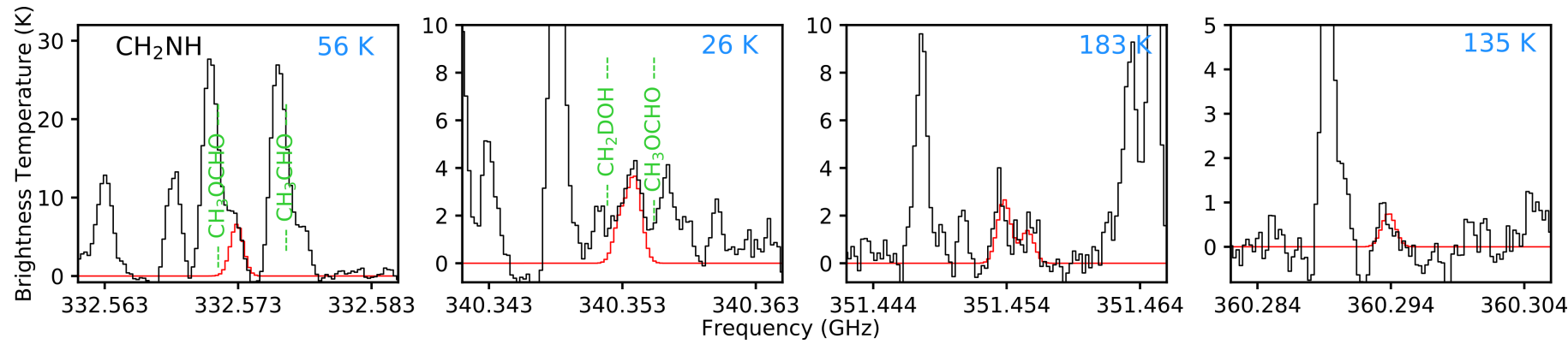

Fig. 1. All detected transitions of $\mathrm{CH}_{2} \mathrm{NH}$ in the PILS spectrum at one beam offset around source B (black), with the synthetic spectrum for $T_{\text {ex }}=100 \mathrm{~K}$ and $N=8.0 \times 10^{14} \mathrm{~cm}^{-2}$ (red) and other known species indicated in green. The upper state energy of each $\mathrm{CH}_{2} \mathrm{NH}$ transition is indicated in blue.

particularly due to the large number of blended lines in the PILS dataset. The best-fit model results are listed in Table 1.

For the non-detected species the formalism in Ligterink et al. (2015) is used to derive upper limit column densities based on the $3 \sigma$ upper limit line intensities of the strongest transitions in line-free ranges of the PILS data. The $1 \sigma$ limit is given by $1.1 \cdot \sqrt{\delta v \cdot F W H M} \cdot$ RMS, where the factor 1.1 accounts for a $10 \%$ calibration uncertainty, $\delta v$ the velocity resolution of the data $\left(0.2 \mathrm{~km} \mathrm{~s}^{-1}\right)$, FWHM is the line width at the one beam offset position in source B $\left(1 \mathrm{~km} \mathrm{~s}^{-1}\right)$ and RMS the noise in mJy beam ${ }^{-1}$ bin $^{-1}$.

\section{Results}

Spectral lines from $\mathrm{CH}_{2} \mathrm{NH}, \mathrm{NO}$, and $\mathrm{N}_{2} \mathrm{O}$ emission are detected, while those of $\mathrm{CH}_{3} \mathrm{NH}_{2}$ and $\mathrm{NH}_{2} \mathrm{OH}$ are not. An overview of the detected transitions is presented in Table A.1. Figures 1-3 show the detected transitions of $\mathrm{CH}_{2} \mathrm{NH}$, NO, and $\mathrm{N}_{2} \mathrm{O}$ towards source $\mathrm{B}$, with synthetic spectra overplotted.

$\mathrm{CH}_{2} \mathrm{NH}$ is detected for the first time towards a low-mass protostellar source. A total of 18 hyperfine transitions in four different spectral features are detected. The first feature shows up at $332.575 \mathrm{GHz}$ and is blended with a neighbouring methylformate $\left(\mathrm{CH}_{3} \mathrm{OCHO}\right)$ line. At $340.354 \mathrm{GHz}$ five hyperfine lines form a distinct feature that is unblended with any other molecule. Around $351.455 \mathrm{GHz}$ a distinct double peak feature is found and at $360.294 \mathrm{GHz}$ the fourth feature is seen. These last three features are found to be unblended. ALMA observations in bands 3, 4, 6, and 9 towards IRAS 16293 were used to search for additional lines, but spectral features of $\mathrm{CH}_{2} \mathrm{NH}$ fall outside the spectral windows of these observations. Publicly available data of the single dish TIMASSS survey towards IRAS 16293 (Caux et al. 2011) were analysed for $\mathrm{CH}_{2} \mathrm{NH}$ spectral features, but no lines were detected, suggesting that the emission indeed arises mostly from a compact source.
Upper state energies $\left(E_{\text {up }}\right)$ of the detected features range from 26 to $183 \mathrm{~K}$, making it possible to constrain the excitation temperature. Using a grid of models, the emission of this species can be fitted with excitation temperatures ranging between 70 and $120 \mathrm{~K}$ and column densities of $6.0 \times 10^{14}-10.0 \times 10^{14} \mathrm{~cm}^{-2}$. Outside this temperature range synthetic spectra cannot reproduce the observed spectrum, as can be seen in Fig. B.1 for fits at $T_{\mathrm{ex}}=50$ and $150 \mathrm{~K}$. The peak velocity is found to be $2.7 \mathrm{~km} \mathrm{~s}^{-1}$. For the best fits, no anti-coincidence is found between the synthetic and observed spectrum. Figure 1 shows the synthetic spectrum at $T_{\mathrm{ex}}=100 \mathrm{~K}$ and $N=8.0 \times 10^{14} \mathrm{~cm}^{-2}$.

Five NO transitions, each with an upper state energy of $36 \mathrm{~K}$, are detected. A number of NO lines at $E_{\text {up }}=209 \mathrm{~K}$ are in the spectral range covered by the data, but are not detected. The excitation temperature can therefore be constrained to be lower than $150 \mathrm{~K}$, otherwise anti-coincidences with the $E_{\text {up }}=209 \mathrm{~K}$ lines in the synthetic spectrum show up, as can be seen in Fig. B.2. The emission can be fitted with $T_{\text {ex }}=40-150 \mathrm{~K}$ and $N=1.5 \times 10^{16}-2.5 \times 10^{16} \mathrm{~cm}^{-2}$. A peak velocity of $V_{\text {peak }}=2.5 \mathrm{~km} \mathrm{~s}^{-1}$ is found for the NO lines, slightly offset from the $V_{\mathrm{LSR}}=2.7 \mathrm{~km} \mathrm{~s}^{-1}$ of source B. A similar offset is seen for other species in the PILS dataset, specifically acetaldehyde and ethylene oxide (Lykke et al. 2017; Jørgensen et al. 2018). Note that seven NO lines have already been detected towards the same source in the TIMASSS survey by Caux et al. (2011). These lines do not arise from the same regions. The lines from the TIMASSS survey are emitted in the cold envelope and source A, since they show a $V_{\text {LSR }}$ of $\sim 4.0 \mathrm{~km} \mathrm{~s}^{-1}$ (Caux et al. 2011), while the lines in the PILS data come from the hot core region in source B. Figure 2 shows the synthetic model to the observational data at an excitation temperature of $100 \mathrm{~K}$ and column density of $2.0 \times 10^{16} \mathrm{~cm}^{-2}$.

Three $\mathrm{N}_{2} \mathrm{O}$ transitions fall in the frequency range of the PILS data, one $v=0$ line with $E_{\text {up }}=127 \mathrm{~K}$ and two $v_{2}=1$ lines with $E_{\text {up }}=973 \mathrm{~K}$. In the observed spectrum a feature is found that 

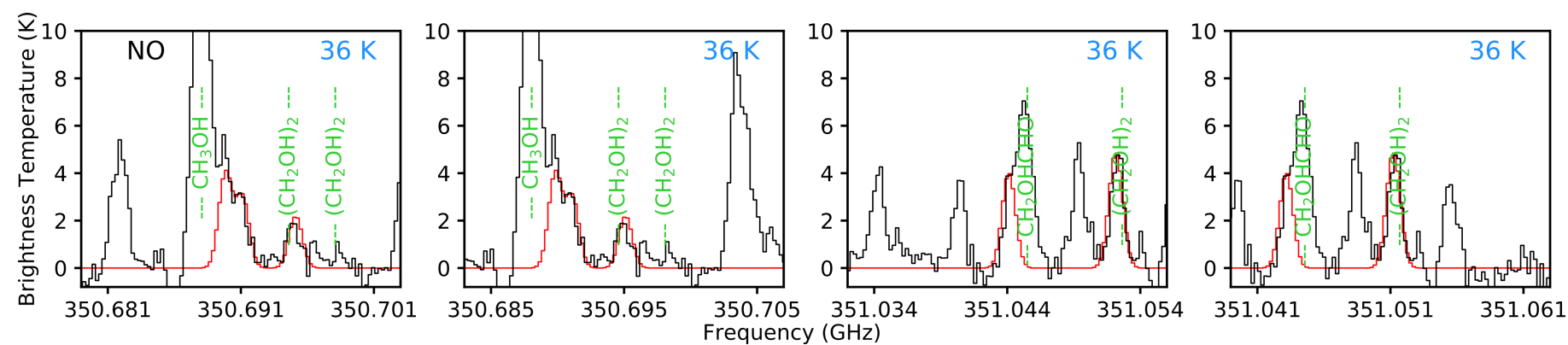

Fig. 2. All detected transitions of NO in the PILS spectrum at one beam offset around source B (black), with the synthetic spectrum for $T_{\mathrm{ex}}=100 \mathrm{~K}$ and $N=2.0 \times 10^{16} \mathrm{~cm}^{-2}$ (red) and other known species indicated in green. The upper state energy of each NO transition is indicated in blue.

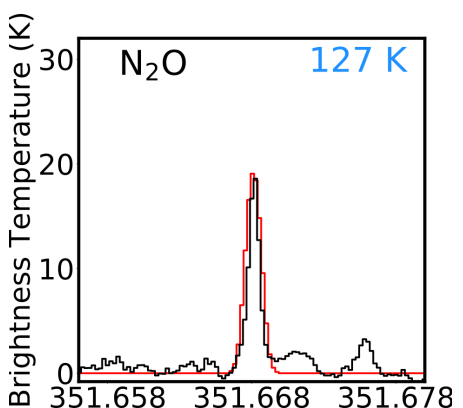

Fig. 3. The $\mathrm{N}_{2} \mathrm{O}$ transition identified in the PILS spectrum at one beam offset around source B (black), with the synthetic spectrum for $T_{\text {ex }}=100 \mathrm{~K}$ and $N=5.0 \times 10^{16} \mathrm{~cm}^{-2}$ (red). The upper state energy of the transition is indicated in blue.

fits the $v=0$ line at $351.667 \mathrm{GHz}$. Since no other known species were found to correspond to this feature, a tentative detection of $\mathrm{N}_{2} \mathrm{O}$ can be claimed. Similar to $\mathrm{NO}, V_{\text {peak }}=2.5 \mathrm{~km} \mathrm{~s}^{-1}$ fits the position of this line. Based on the non-detection of the $v_{2}=$ 1 lines, the excitation temperature can be constrained to be lower than $350 \mathrm{~K}$.

To further support this assignment, additional datasets were checked. No $\mathrm{N}_{2} \mathrm{O}$ lines were covered in ALMA Band 3, 4, 6, and 9 datasets towards IRAS 16293. However, analysis of data from the TIMASSS survey resulted in the identification of a number of features. Four $\mathrm{N}_{2} \mathrm{O}$ lines are found to be unblended (see Fig. C.1). Based on Gaussian fitting of the profiles, the peak velocity of the four lines is $2.5 \mathrm{~km} \mathrm{~s}^{-1}$, similar to the $\mathrm{N}_{2} \mathrm{O}$ transition detected towards source B in the PILS survey. However, velocity components at $3.9 \mathrm{~km} \mathrm{~s}^{-1}$, resulting from source A or extended emission, cannot be entirely ruled out. Based on a comparison of the $\mathrm{N}_{2} \mathrm{O} 351.667 \mathrm{GHz}$ line flux of $394 \mathrm{mJy} \mathrm{beam}^{-1} \mathrm{~km} \mathrm{~s}^{-1}$ or $15.7 \mathrm{~K} \mathrm{~km} \mathrm{~s}^{-1}$ in the ALMA-PILS and $0.2 \mathrm{~K} \mathrm{~km} \mathrm{~s}^{-1}$ in the JCMT-TIMASSS data, the emitting area in the TIMASSS data is found to be around 1".6. This is supported by the integrated emission map of the $\mathrm{N}_{2} \mathrm{O} 351.667 \mathrm{GHz}$ line (Fig. 4), where the emission has a larger FWHM than other species. The best fit to the optically thin lines in the TIMASSS data is found for $T_{\mathrm{ex}}=$ $68 \mathrm{~K}$ and $N=1.7 \times 10^{16} \mathrm{~cm}^{-2}$ (see Fig. C.2). Note that the precise source size for $\mathrm{N}_{2} \mathrm{O}$ can change the excitation temperature by a couple tens of Kelvin, but can be constrained to be below $100 \mathrm{~K}$, and column density by $\pm 25 \%$. See Appendix C for further details.

In the PILS data, at $T_{\text {ex }}=100 \mathrm{~K}$ a column density of $5.0 \times 10^{16} \mathrm{~cm}^{-2}$ is derived for the $\mathrm{N}_{2} \mathrm{O} 351.667 \mathrm{GHz}$ transition, see Fig. 3. However, since the TIMASSS data indicate that the excitation temperature is likely lower than $100 \mathrm{~K}$, this line was fitted with $T_{\mathrm{ex}}=25-100 \mathrm{~K}$. For these temperatures, emission is found to be optically thick and the column density is constrained to be $\geq 5.0 \times 10^{16} \mathrm{~cm}^{-2}$ for the entire temperature range. Excitation temperatures between 100 and $350 \mathrm{~K}$ cannot be neglected and for this range column densities of $\geq 4.0 \times 10^{16} \mathrm{~cm}^{-2}$ are derived.

Finally, lines of the ${ }^{15} \mathrm{~N}$ and ${ }^{18} \mathrm{O}$ isotopologues of $\mathrm{N}_{2} \mathrm{O}$ were searched for in the PILS data, but not detected to levels above the standard ${ }^{14} \mathrm{~N} /{ }^{15} \mathrm{~N}$ and ${ }^{16} \mathrm{O} /{ }^{18} \mathrm{O}$ ISM ratios (see Wilson 1999; Milam et al. 2005). Both the ${ }^{15} \mathrm{~N}^{14} \mathrm{NO}$ and ${ }^{14} \mathrm{~N}^{15} \mathrm{NO}$ transition are blended with an unknown feature and a $\mathrm{HN}^{13} \mathrm{CO}$ line, respectively. For $\mathrm{N}_{2}^{18} \mathrm{O}$ an upper limit column density of $\leq 1 \times 10^{15} \mathrm{~cm}^{-2}$ at $T_{\mathrm{ex}}=100 \mathrm{~K}$ is determined, resulting in $\mathrm{N}_{2} \mathrm{O} / \mathrm{N}_{2}^{18} \mathrm{O}>40$ compared to an expected ${ }^{18} \mathrm{O} /{ }^{16} \mathrm{O}$ ratio of 560 (Wilson 1999).

Figure 4 shows the emission maps of the $332.572 \mathrm{GHz}$ line of $\mathrm{CH}_{2} \mathrm{NH}$, the $351.052 \mathrm{GHz}$ line of $\mathrm{NO}$, and the $351.668 \mathrm{GHz}$ line of $\mathrm{N}_{2} \mathrm{O}$ towards source $\mathrm{B}$. Emission is generally found to be compact and compares well with emission maps of other molecules towards source $\mathrm{B}$, such as $\mathrm{NH}_{2} \mathrm{CHO}$ (Coutens et al. 2016). Emission of $\mathrm{N}_{2} \mathrm{O}$ is more extended than that of NO.

Transitions of both $\mathrm{CH}_{3} \mathrm{NH}_{2}$ and $\mathrm{NH}_{2} \mathrm{OH}$ are not detected and therefore upper limit column densities are determined. For $\mathrm{CH}_{3} \mathrm{NH}_{2}$, the $6_{1} \rightarrow 5_{0}$ transition at $357.440 \mathrm{GHz}$ best constrains the upper limit column density. For a $3 \sigma$ upper limit line intensity of $23 \mathrm{mJy} \mathrm{km} \mathrm{s}^{-1}$, the upper limit column densities versus the rotational temperatures are plotted in Fig. D.1. At $T_{\mathrm{ex}}=100 \mathrm{~K}$, the upper limit column density is $\leq 5.3 \times 10^{14} \mathrm{~cm}^{-2}$.

$\mathrm{NH}_{2} \mathrm{OH}$ has three strong transitions at 352.522, 352.730, and $352.485 \mathrm{GHz}$ for the $7_{0} \rightarrow 6_{0}, 7_{1} \rightarrow 6_{1}, 7_{2} \rightarrow 6_{2}$ transitions, respectively. Slightly different RMS noise conditions apply around each of these transitions, resulting in a $3 \sigma$ of 27 , 21 , and $27 \mathrm{mJy} \mathrm{km} \mathrm{s}^{-1}$, respectively. The upper limit column density versus rotational temperature plot is shown in Fig. D.2. The transition at $352.522 \mathrm{GHz}$ constrains the column density most, resulting in an upper limit column density of $\mathrm{NH}_{2} \mathrm{OH}$ of $\leq 3.7 \times 10^{14} \mathrm{~cm}^{-2}$ at $T_{\mathrm{ex}}=100 \mathrm{~K}$.

Table 1 lists the column densities and excitation temperatures for the five molecules under investigation in this work. For the three detected species the column density and excitation temperature ranges that can fit the emission are listed. For the non-detected species $\mathrm{CH}_{3} \mathrm{NH}_{2}$ and $\mathrm{NH}_{2} \mathrm{OH}$ the upper limit column density is determined for $T_{\mathrm{ex}}=100 \mathrm{~K}$. The typical uncertainty of the column densities of these upper limits for a reasonable range of excitation temperatures is a factor of $\sim 2$ (see Appendix D).

\section{Astrochemical implications}

To put the results into context, the column density ratios between the molecules studied here and formamide $\left(\mathrm{NH}_{2} \mathrm{CHO}\right)$, methanol $\left(\mathrm{CH}_{3} \mathrm{OH}\right)$, and molecular hydrogen $\left(\mathrm{H}_{2}\right)$ are computed 
Table 2. Comparison of $\mathrm{NO}$ and $\mathrm{N}_{2} \mathrm{O}$ abundances at one beam offset around source $\mathrm{B}$.

\begin{tabular}{lcccl}
\hline \hline Source & $\mathrm{NO} / \mathrm{H}_{2}$ & $\mathrm{~N}_{2} \mathrm{O} / \mathrm{H}_{2}$ & $\mathrm{NO} / \mathrm{N}_{2} \mathrm{O}$ & Reference \\
\hline IRAS 16293-2422B & $\leq 1.7 \times 10^{-9 a}$ & $\sim 3.3 \times 10^{-9 b}$ & $\leq 0.5$ & This work \\
\hline Sgr B2(M) & $\sim 9 \times 10^{-9}$ & $\sim 1 \times 10^{-9}$ & $\sim 10$ & Ziurys et al. (1994) \\
Sgr B2(N) & $1.32 \times 10^{-8}$ & $1.5 \times 10^{-9}$ & 8.8 & Halfen et al. (2001) \\
\hline Sgr B2 & $1 \times 10^{-8}$ & - & - & Liszt \& Turner (1978) \\
L134N & $6 \times 10^{-8}$ & - & - & McGonagle et al. (1990) \\
NGC 1333 IRAS 4A & $2.3 \times 10^{-8}$ & - & - & Ylldiz et al. (2013) \\
L1157-B1 & $4-7 \times 10^{-7}$ & - & - & Codella et al. (2018) \\
SVS13-A & $\leq 3 \times 10^{-7}$ & - & - & Codella et al. (2018) \\
\hline
\end{tabular}

Notes. ${ }^{(a)}$ Ratio determined from a lower limit $\mathrm{H}_{2}$ column density. ${ }^{(b)}$ Ratio determined from lower limit $\mathrm{N}_{2} \mathrm{O}$ and $\mathrm{H}_{2}$ column densities.
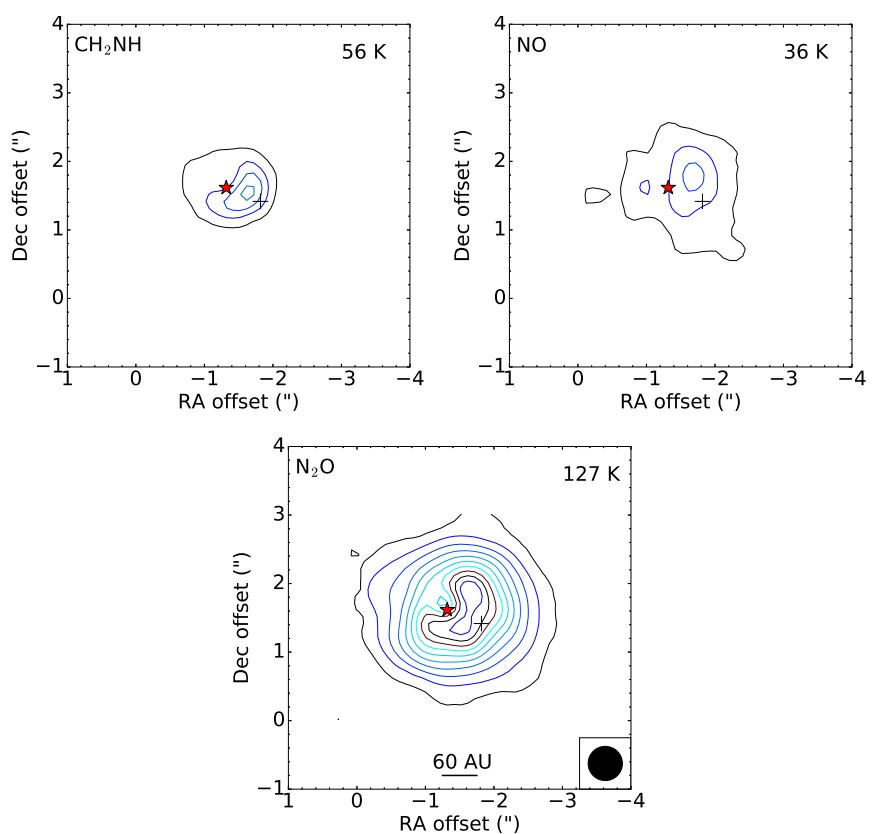

Fig. 4. Integrated emission maps of the $332.572 \mathrm{GHz}$ line of $\mathrm{CH}_{2} \mathrm{NH}$, the $351.052 \mathrm{GHz}$ line of $\mathrm{NO}$, and the $351.668 \mathrm{GHz}$ line of $\mathrm{N}_{2} \mathrm{O}$. The emission is integrated between 2.2 and $3.2 \mathrm{~km} \mathrm{~s}^{-1}$. The axes show the position offset from phase centre of the observations. Contour levels start at $30 \mathrm{mJy} \mathrm{km} \mathrm{s}^{-1}$ and increase in steps of $45 \mathrm{mJy} \mathrm{km} \mathrm{s}^{-1}$. The red star marks the peak continuum position and the black cross marks the one beam offset position where the spectra are analysed.

and compared with other sources. The column densities of these reference species towards the same, one beam offset position in source $\mathrm{B}$ are: $\mathrm{NH}_{2} \mathrm{CHO}=1 \times 10^{16}, \mathrm{CH}_{3} \mathrm{OH}=1 \times 10^{19}$, and $\mathrm{H}_{2}>1.2 \times 10^{25} \mathrm{~cm}^{-2}$ (Coutens et al. 2016; Jørgensen et al. 2016). The $\mathrm{H}_{2}$ lower limit column density is determined towards the continuum peak position of source B, but the same lower limit should hold for the one beam offset position being analysed in this paper, where the dust emission is still optically thick. Earlier results for Orion KL and for some Sgr B2 studies, used to put our ratios into context, are based on single dish data, whereas in this work interferometric data are used. It is important to stress that differences in abundance ratios do not necessarily reflect chemical differences, but could arise from the fact that single dish observations generally probe larger spatial scales and are more affected by beam dilution (see Jørgensen et al. 2016).

The $\mathrm{NH}_{2} \mathrm{OH}$ upper limit abundance of $N\left(\mathrm{NH}_{2} \mathrm{OH}\right) / N\left(\mathrm{H}_{2}\right)$ $\leq 3.1 \times 10^{-11}$ found in this work is comparable to upper limit abundances found for high-mass sources by Pulliam et al. (2012), but significantly lower than the ice abundances of $7 \times 10^{-9} \mathrm{~N}\left(\mathrm{H}+\mathrm{H}_{2}\right)$ found with a dark cloud model in Fedoseev et al. (2012). One explanation could be that the reaction barriers in this model are too low or that destruction or competing pathways are missing. It could also be that the dominant pathway to $\mathrm{NH}_{2} \mathrm{OH}$ is a gas-phase formation route, although such a route would likely also be hindered by a large reaction barrier or subject to efficient destruction or competing pathways. The more extensive gas-grain model of Garrod (2013) also overpredicts this species, although the predicted abundance is lower by at least an order of magnitude. The full comparison of the hydroxylamine upper limit abundance compared with literature values is given in Table E.1. One example of missing destructions reactions is given by laboratory experiments which show that thermal processing of $\mathrm{NH}_{2} \mathrm{OH}: \mathrm{H}_{2} \mathrm{O}$ mixtures results in the conversion of $\mathrm{NH}_{2} \mathrm{OH}$ into $\mathrm{HNO}, \mathrm{NH}_{3}$, and $\mathrm{O}_{2}$ before the onset of desorption (Jonusas \& Krim 2016). Also, UV processing of ice mixtures containing $\mathrm{NH}_{2} \mathrm{OH}$ results in the efficient destruction of this molecule (Fedoseev et al. 2016). The low gas-phase abundance of $\mathrm{NH}_{2} \mathrm{OH}$ limits its involvement in gas-phase production routes of amino acids.

The NO abundance in IRAS $16293 \mathrm{~B}\left(N(\mathrm{NO}) / N\left(\mathrm{H}_{2}\right) \leq 1.7 \times\right.$ $10^{-9}$, given as an upper limit due to the lower limit $\mathrm{H}_{2}$ column density) is low compared to observational and modelling studies of dark clouds, where NO abundances of $10^{-8}-10^{-6}$ are found (e.g. McGonagle et al. 1990; Visser et al. 2011). The IRAS 16293B abundance of NO is much more stringent than the NO upper limit of $\leq 3 \times 10^{-7}$ derived towards the envelope of SVS13-A and also substantially lower than the NO abundance of $(4-7) \times 10^{-6}$ towards the L1157-B1 shock (Codella et al. 2018). Modelling shows that NO is readily lost in the ice by conversion to other species, mainly $\mathrm{NH}_{2} \mathrm{OH}$ (Y1ldiz et al. 2013), and in the gas-phase by photodissociation reactions in the hot core (Visser et al. 2011) and thus could explain the depletion of $\mathrm{NO}$ in IRAS 16293B. The high $\mathrm{N}_{2} \mathrm{O}$ abundance may indicate other loss pathways of $\mathrm{NO}$ as well. $\mathrm{N}_{2} \mathrm{O}$ is found in laboratory ice experiments as a side product of NO hydrogenation and UV irradiation (Congiu et al. 2012; Fedoseev et al. 2012,2016 ) and suggested to form via the reaction $\mathrm{NO}+\mathrm{NH}$ in warm gas (Halfen et al. 2001). The $N(\mathrm{NO}) / N\left(\mathrm{~N}_{2} \mathrm{O}\right) \leq 0.5$ ratio hints to a scenario where $\mathrm{NO}$ is at least partly converted to $\mathrm{N}_{2} \mathrm{O}$ in the ice and/or gas surrounding IRAS 16293B. Interestingly the abundance ratio in IRAS 16293B contrasts with other known abundances toward Sgr B2, which have $N(\mathrm{NO}) / N\left(\mathrm{~N}_{2} \mathrm{O}\right) \sim 10$ (Ziurys et al. 1994; Halfen et al. 2001), see Table 2. 
Table 3. Comparison of $\mathrm{CH}_{3} \mathrm{NH}_{2}$ abundances at one beam offset around source B.

\begin{tabular}{lcccl}
\hline \hline Source & $\mathrm{CH}_{3} \mathrm{NH}_{2} / \mathrm{CH}_{2} \mathrm{NH}$ & $\mathrm{CH}_{3} \mathrm{NH}_{2} / \mathrm{NH}_{2} \mathrm{CHO}$ & $\mathrm{CH}_{3} \mathrm{NH}_{2} / \mathrm{CH}_{3} \mathrm{OH}$ & Reference \\
\hline IRAS 16293-2422B & $\leq 0.88$ & $\leq 0.053$ & $\leq 5.3 \times 10^{-5}$ & This work \\
\hline Sgr B2 & $\sim 1$ & 0.57 & 0.017 & Turner (1991) \\
Sgr B2(M) & 31 & 3.2 & 0.008 & Belloche et al. (2013) \\
Sgr B2(N) & 0.75 & 0.43 & 0.034 & Belloche et al. (2013) \\
Sgr B2(N) & 5.5 & - & - & Halfen et al. (2013) \\
Sgr B2(N) & 7.1 & 2.1 & 0.1 & Neill et al. (2014) \\
\hline Hot core model & - & $1.1-1.7$ & $0.034-0.13$ & Garrod et al. (2008) \\
Hot core model & $0.5-7.3$ & $0.2-2.3$ & $1.8-7.3 \times 10^{-3}$ & Garrod (2013) \\
\hline
\end{tabular}

Notes. ${ }^{(a)}$ Abundance ranges taken from the $\mathrm{F}($ ast $), \mathrm{M}$ (edium), and $\mathrm{S}$ (low) warm-up models.

Table 4. Comparison of $\mathrm{CH}_{2} \mathrm{NH}$ abundances at one beam offset around source $\mathrm{B}$.

\begin{tabular}{lcccl}
\hline \hline Source & $\mathrm{CH}_{2} \mathrm{NH} / \mathrm{NH}_{2} \mathrm{CHO}$ & $\mathrm{CH}_{2} \mathrm{NH} / \mathrm{CH}_{3} \mathrm{OH}$ & $\mathrm{CH}_{2} \mathrm{NH} / \mathrm{H}_{2}$ & Reference \\
\hline IRAS 16293-2422B & 0.08 & $8.0 \times 10^{-5}$ & $<6.7 \times 10^{-11}$ & This work \\
\hline Sgr B2 & $\sim 0.57$ & $\sim 0.017$ & - & Turner (1991) \\
Sgr B2(M) & 0.10 & $5.5 \times 10^{-4}$ & - & Belloche et al. (2013) \\
Sgr B2(N) & 0.57 & 0.044 & - & Belloche et al. (2013) \\
Sgr B2(N) & - & - & $3.0 \times 10^{-10}$ & Halfen et al. (2013) \\
Sgr B2(N) & 0.30 & 0.014 & $8.8 \times 10^{-9}$ & Neill et al. (2014) \\
Orion KL & - & $1.9 \times 10^{-3}$ & $4.2 \times 10^{-9}$ & Crockett et al. (2014) \\
\hline Hot core model & $0.03-5.17$ & $1.0-3.9 \times 10^{-3}$ & $6.8-80 \times 10^{-9}$ & Garrod (2013) \\
\hline
\end{tabular}

Notes. ${ }^{(a)}$ Abundance ranges taken from the $\mathrm{F}($ ast $), \mathrm{M}($ edium), and $\mathrm{S}(\mathrm{low})$ warm-up models.

Table 3 lists the abundance ratios of $\mathrm{CH}_{3} \mathrm{NH}_{2}$ in IRAS 16293B, Sgr B2 and hot core models by Garrod et al. (2008) and Garrod (2013). The abundance ratios of $\mathrm{CH}_{3} \mathrm{NH}_{2} / \mathrm{CH}_{2} \mathrm{NH}$ are slightly lower in IRAS $16293 \mathrm{~B}$ compared to Sgr B2 and the models of Garrod (2013), but ratios with respect to $\mathrm{NH}_{2} \mathrm{CHO}$ and $\mathrm{CH}_{3} \mathrm{OH}$ are lower by at least one to two orders of magnitude. Abundances of $\mathrm{CH}_{2} \mathrm{NH}$ relative to $\mathrm{NH}_{2} \mathrm{CHO}, \mathrm{CH}_{3} \mathrm{OH}$, and $\mathrm{H}_{2}$ are given in Table 4. The observed $\mathrm{CH}_{2} \mathrm{NH} / \mathrm{NH}_{2} \mathrm{CHO}$ abundance ratio in IRAS $16293 \mathrm{~B}$ is lower than that in Sgr B2, but in range of model predictions. This can indicate that $\mathrm{NH}_{2} \mathrm{CHO}$ is overpredicted in the models. The ratios with respect to $\mathrm{CH}_{3} \mathrm{OH}$ and $\mathrm{H}_{2}$ are in most cases at least an order of magnitude lower in IRAS 16293B compared to Sgr B2 and models. The comparison of these abundances indicates that the formation of both $\mathrm{CH}_{3} \mathrm{NH}_{2}$ and $\mathrm{CH}_{2} \mathrm{NH}$ is less efficient in the low-mass source IRAS 16293B and overpredicted in models.

$\mathrm{CH}_{3} \mathrm{NH}_{2}$ was mass spectrometrically detected on the comet 67P/C-G (Goesmann et al. 2015). However, the recent detection with the ROSINA-DFMS instrument indicates that it is present at a lower abundance, below the $1 \%$ level with respect to water, than initially thought (Altwegg et al. 2017), resulting in a $\mathrm{CH}_{3} \mathrm{NH}_{2} / \mathrm{H}_{2} \mathrm{O}$ abundance of $1.2 \times 10^{-4}$. Since IRAS $16293 \mathrm{~B}$ is assumed to resemble an early formation stage of our solar system, the low abundance of $\mathrm{CH}_{3} \mathrm{NH}_{2}$ in $67 \mathrm{P} / \mathrm{C}-\mathrm{G}$ and nondetection in IRAS 16293B suggest that $\mathrm{CH}_{3} \mathrm{NH}_{2}$ is not efficiently formed in these environments. Furthermore, the low abundance of $\mathrm{CH}_{3} \mathrm{NH}_{2}$ limits the relevance of amino acid formation routes involving this species. Conversely, the detection of $\mathrm{CH}_{2} \mathrm{NH}$ makes amino acid formation routes involving this molecule a more likely possibility.
Acknowledgements. We would like to thank the anonymous referee for the useful inputs given to this paper. This letter makes use of the following ALMA data: ADS/JAO.ALMA\#2013.1.00278.S. ALMA is a partnership of ESO (representing its member states), NSF (USA), and NINS (Japan), together with NRC (Canada) and NSC and ASIAA (Taiwan), in cooperation with the Republic of Chile. The Joint ALMA Observatory is operated by ESO, AUI/NRAO and NAOJ. Astrochemistry in Leiden is supported by the European Union A-ERC grant 291141 CHEMPLAN, by the Netherlands Research School for Astronomy (NOVA) and by a Royal Netherlands Academy of Arts and Sciences (KNAW) professor prize. The group of J.K.J. acknowledges support from a Lundbeck Foundation Group Leader Fellowship, as well as the ERC under the European Union's Horizon 2020 research and innovation programme through ERC Consolidator Grant S4F (grant agreement No. 646908). Research at the Centre for Star and Planet Formation is funded by the Danish National Research Foundation. A.C. postdoctoral grant is funded by the ERC Starting Grant 3DICE (grant agreement 336474). M.N.D. acknowledges the financial support of the Center for Space and Habitability (CSH) Fellowship and the IAU Gruber Foundation Fellowship.

\section{References}

Altwegg, K., Balsiger, H., Bar-Nun, A., et al. 2016, Sci. Adv., 2, e1600285 Altwegg, K., Balsiger, H., Berthelier, J. J., et al. 2017, MNRAS, 469, S130 Barrientos, C., Redondo, P., Largo, L., Rayón, V. M., \& Largo, A. 2012, ApJ, 748, 99

Belloche, A., Müller, H. S. P., Menten, K. M., Schilke, P., \& Comito, C. 2013, A\&A, 559, A47

Blagojevic, V., Petrie, S., \& Bohme, D. K. 2003, MNRAS, 339, L7 Bossa, J.-B., Duvernay, F., Theulé, P., et al. 2009, A\&A, 506, 601 Caux, E., Kahane, C., Castets, A., et al. 2011, A\&A, 532, A23 Codella, C., Viti, S., Lefloch, B., et al. 2018, MNRAS, 474, 5694 Congiu, E., Fedoseev, G., Ioppolo, S., et al. 2012, ApJ, 750, L12

Coutens, A., Jørgensen, J. K., van der Wiel, M. H. D., et al. 2016, A\&A, 590, L6 Crockett, N. R., Bergin, E. A., Neill, J. L., et al. 2014, ApJ, 787, 112 Danger, G., Borget, F., Chomat, M., et al. 2011, A\&A, 535, A47

Dickens, J. E., Irvine, W. M., DeVries, C. H., \& Ohishi, M. 1997, ApJ, 479, 307 Elsila, J. E., Glavin, D. P., \& Dworkin, J. P. 2009, Meteorit. Planet. Sci., 44, 1323 
Fedoseev, G., Ioppolo, S., Lamberts, T., et al. 2012, J. Chem. Phys., 137, 054714 Fedoseev, G., Chuang, K.-J., van Dishoeck, E. F., Ioppolo, S., \& Linnartz, H. 2016, MNRAS, 460, 4297

Förstel, M., Bergantini, A., Maksyutenko, P., Góbi, S., \& Kaiser, R. I. 2017, ApJ, 845,83

Garrod, R. T. 2013, ApJ, 765, 60

Garrod, R. T., Widicus Weaver, S. L., \& Herbst, E. 2008, ApJ, 682, 283

Goesmann, F., Rosenbauer, H., Bredehoft, J. H., et al. 2015, Science, 349, aab0689

Halfen, D. T., Apponi, A. J., \& Ziurys, L. M. 2001, ApJ, 561, 244

Halfen, D. T., Ilyushin, V. V., \& Ziurys, L. M. 2013, ApJ, 767, 66

He, J., Vidali, G., Lemaire, J.-L., \& Garrod, R. T. 2015, ApJ, 799, 49

Holtom, P. D., Bennett, C. J., Osamura, Y., Mason, N. J., \& Kaiser, R. I. 2005, ApJ, 626, 940

Ilyushin, V. V., Alekseev, E. A., Dyubko, S. F., Motiyenko, R. A., \& Hougen, J. T. 2005, J. Mol. Spectrosc., 229, 170

Jonusas, M., \& Krim, L. 2016, MNRAS, 459, 1977

Jørgensen, J. K., van der Wiel, M. H. D., Coutens, A., et al. 2016, A\&A, 595, A117

Jørgensen, J. K., Calcutt, H., \& Müller, H. S. P. 2018, A\&A, submitted [arXiv: 1808.08753$]$

Kaifu, N., Morimoto, M., Nagane, K., et al. 1974, ApJ, 191, L135

Kim, Y. S., \& Kaiser, R. I. 2011, ApJ, 729, 68

Kirchhoff, W. H., Johnson, D. R., \& Lovas, F. J. 1973, J. Phys. Chem. Ref. Data, 2,1

Ligterink, N. F. W., Tenenbaum, E. D., \& van Dishoeck, E. F. 2015, A\&A, 576, A35

Ligterink, N. F. W., Coutens, A., Kofman, V., et al. 2017, MNRAS, 469, 2219

Liszt, H. S., \& Turner, B. E. 1978, ApJ, 224, L73

Lykke, J. M., Coutens, A., Jørgensen, J. K., et al. 2017, A\&A, 597, A53

McGonagle, D., Irvine, W. M., Minh, Y. C., \& Ziurys, L. M. 1990, ApJ, 359, 121
McGuire, B. A., Carroll, P. B., Dollhopf, N. M., et al. 2015, ApJ, 812, 76

Milam, S. N., Savage, C., Brewster, M. A., Ziurys, L. M., \& Wyckoff, S. 2005, ApJ, 634, 1126

Morino, I., Yamada, K., Klein, H., et al. 2000, J. Mol. Struct., 517, 367

Müller, H. S. P., Thorwirth, S., Roth, D. A., \& Winnewisser, G. 2001, A\&A, 370 , L49

Müller, H. S. P., Schlöder, F., Stutzki, J., \& Winnewisser, G. 2005, J. Mol. Struct., 742,215

Neill, J. L., Bergin, E. A., Lis, D. C., et al. 2014, ApJ, 789, 8

Nummelin, A., Bergman, P., Hjalmarson, A., et al. 2000, Doktorsavhandlingar vid Chalmers Tekniska Hogskola, 2

Pagani, L., Favre, C., Goldsmith, P. F., et al. 2017, A\&A, 604, A32

Persson, M. V., Jørgensen, J. K., Müller, H. S. P., et al. 2018, A\&A, 610, A54

Pickett, H. M., Cohen, E. A., Waters, J. W., \& Phillips, T. G. 1979, 34th International Symposium on Molecular Spectroscopy, Columbus, OH, USA

Pickett, H. M., Poynter, R. L., Cohen, E. A., et al. 1998, J. Quant. Spec. Radiat. Transf., 60, 883

Pulliam, R. L., McGuire, B. A., \& Remijan, A. J. 2012, ApJ, 751, 1

Snow, J. L., Orlova, G., Blagojevic, V., \& Bohme, D. K. 2007, J. Am. Chem. Soc., 129,9910

Suzuki, T., Ohishi, M., Hirota, T., et al. 2016, ApJ, 825, 79

Theule, P., Borget, F., Mispelaer, F., et al. 2011, A\&A, 534, A64

Ting, W.-J., Chang, C.-H., Chen, S.-E., et al. 2014, J. Opt. Soc. Am. B Opt. Phys., 31, 1954

Turner, B. E. 1991, ApJS, 76, 617

Visser, R., Doty, S. D., \& van Dishoeck E. F. 2011, A\&A, 534, A132

Wilson, T. L. 1999, Rep. Prog. Phys., 62, 143

Woon, D. E. 2002, ApJ, 571, L177

Yıldı, U. A., Acharyya, K., Goldsmith, P. F., et al. 2013, A\&A, 558, A58

Zheng, W., \& Kaiser, R. I. 2010, J. Phys. Chem. A, 114, 5251

Ziurys, L. M., Apponi, A. J., Hollis, J. M., \& Snyder, L. E. 1994, ApJ, 436, L181 
A\&A 619, A28 (2018)

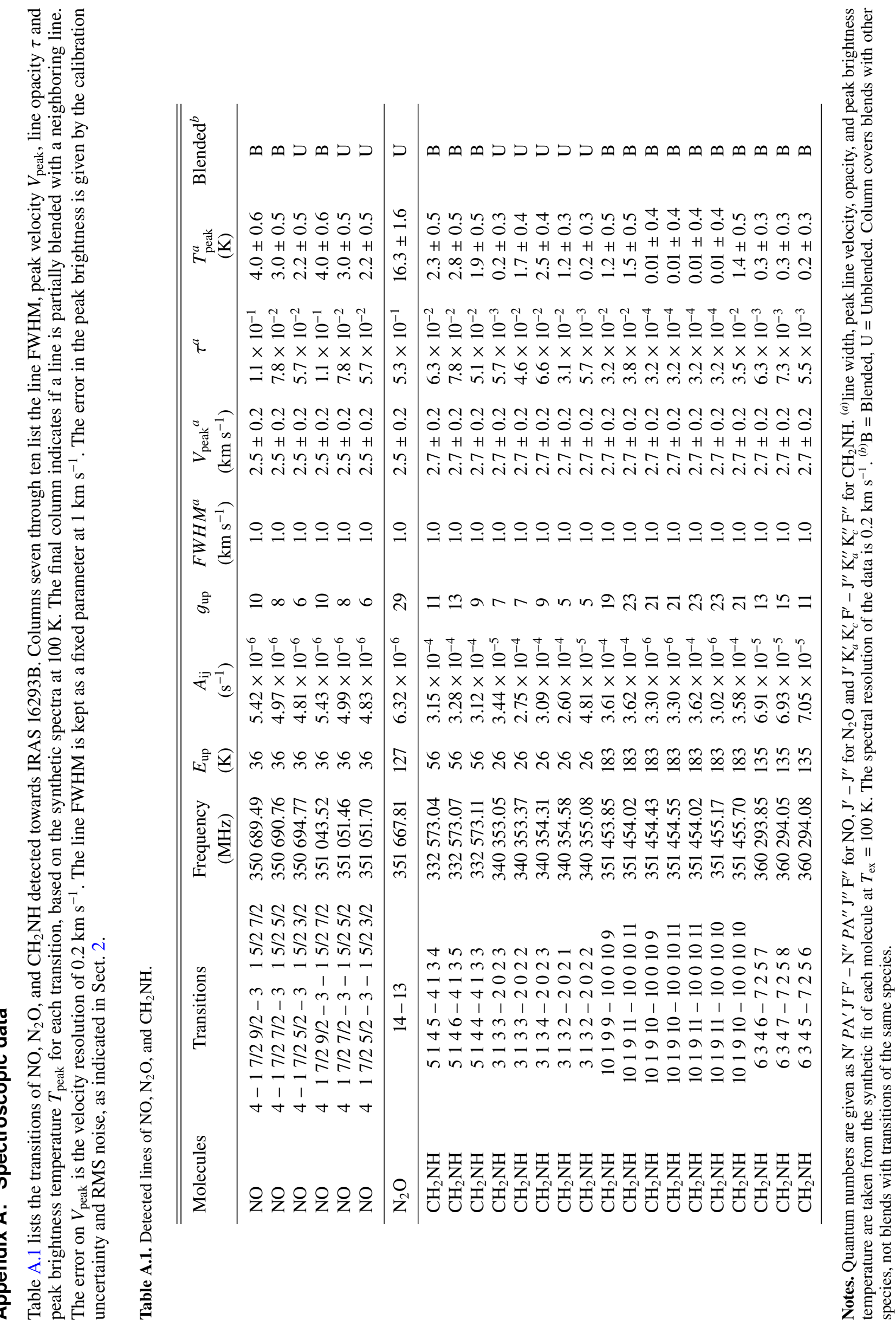




\section{Appendix B: Additional fit spectra of $\mathrm{CH}_{2} \mathrm{NH}$ and NO}

Figure B.1 shows $\mathrm{CH}_{2} \mathrm{NH}$ synthetic spectra at $T_{\mathrm{ex}}=50$ and $150 \mathrm{~K}$. Best fit column densities of $7 \times 10^{14}$ and $8 \times 10^{14} \mathrm{~cm}^{-2}$, respectively, are found. However, clear discrepancies in the fits exist, which are especially visible for the transitions at 340.354 and $351.454 \mathrm{GHz}$
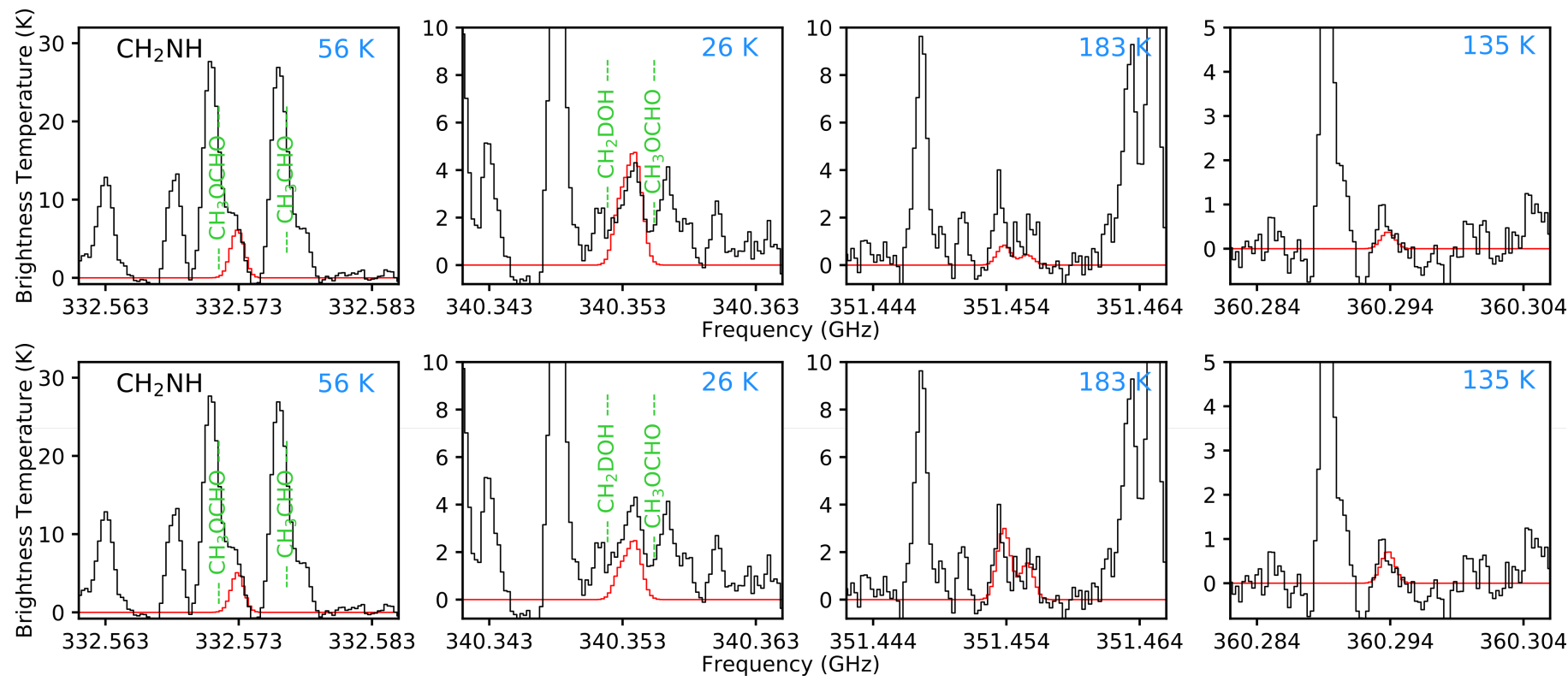

Fig. B.1. Fit models (red) of $\mathrm{CH}_{2} \mathrm{NH}$ at $T_{\mathrm{ex}}=50 \mathrm{~K}$ (top panels) and $T_{\mathrm{ex}}=150 \mathrm{~K}$ (bottom panels) overplotted on the PILS data (black) and other detected species in PILS given in green. Upper state energies of the $\mathrm{CH}_{2} \mathrm{NH}$ transitions are indicated in blue.
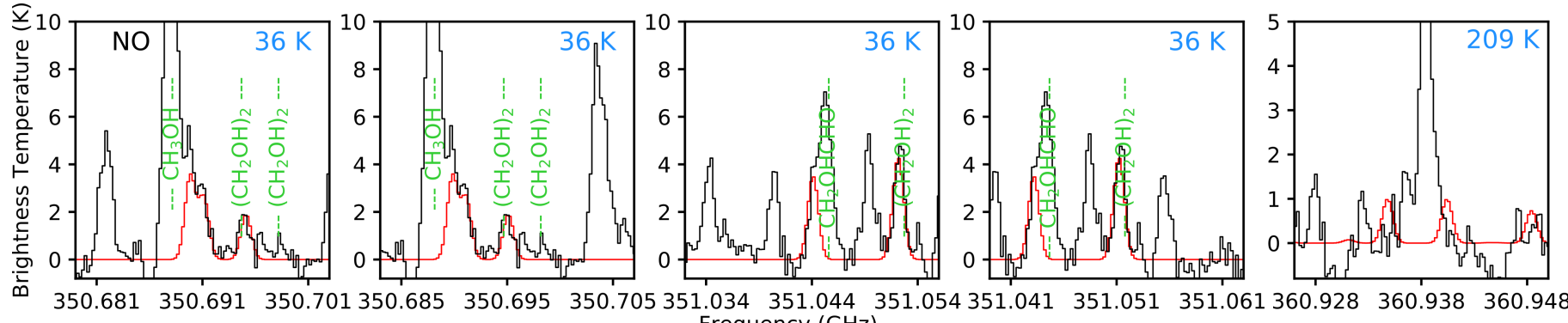
Frequency $(\mathrm{GHz})$

Fig. B.2. Fit models (red) of $\mathrm{NO}$ at $T_{\mathrm{ex}}=150 \mathrm{~K}$ overplotted on the PILS data (black) and other detected species in PILS given in green. Upper state energies of the NO transitions are indicated in blue. 
Appendix C: $\mathrm{N}_{2} \mathrm{O}$ fit of TIMASSS data set
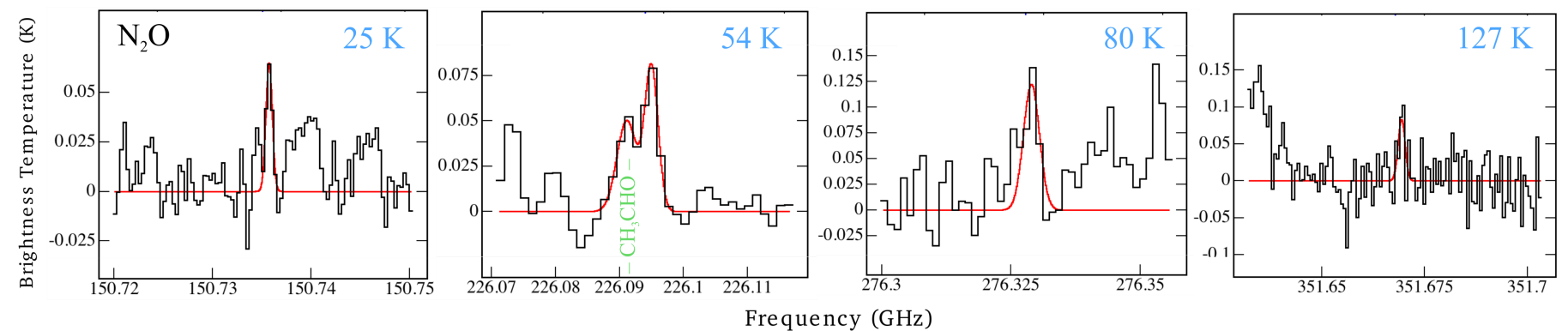

Fig. C.1. Gaussian fits (red) of unblended $\mathrm{N}_{2} \mathrm{O}$ transitions in the single-dish TIMASSS data (black) by Caux et al. (2011). Upper state energies of the transitions are indicated in blue.

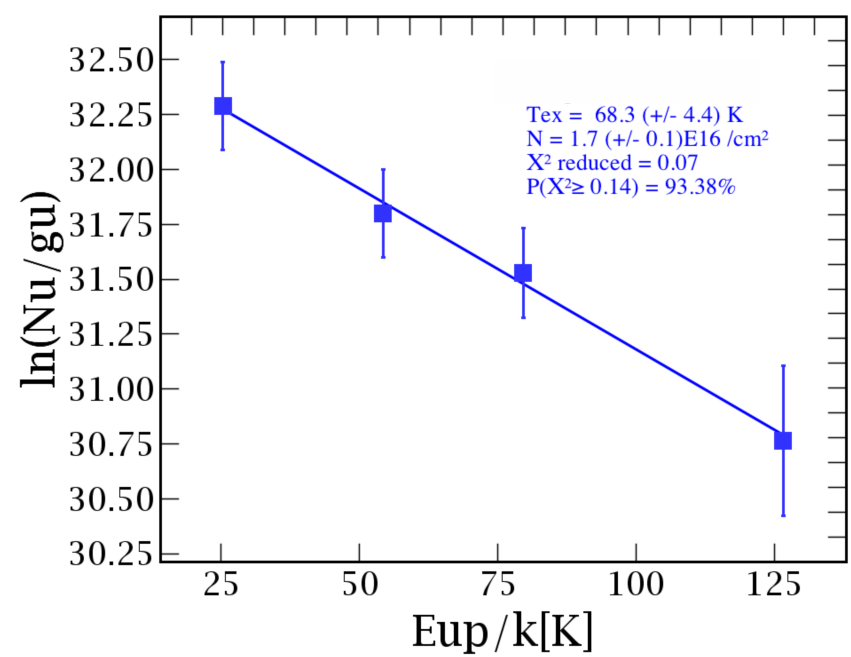

Fig. C.2. Rotational temperature diagram of the four unblended $\mathrm{N}_{2} \mathrm{O}$ transitions found in the TIMASSS dataset, resulting in $T_{\mathrm{ex}}=68 \mathrm{~K}$ and $N=1.7 \times 10^{16} \mathrm{~cm}^{-2}$, for a source size of $1^{\prime \prime} .6$.

Figure C. 1 shows the four unblended lines of $\mathrm{N}_{2} \mathrm{O}$ detected in the TIMASSS survey. All these transitions are velocity shifted to $V_{\text {peak }}=2.5 \mathrm{~km} \mathrm{~s}^{-1}$. Gaussian profiles were fitted and line widths are found between 1.4 and $3.3 \mathrm{~km} \mathrm{~s}^{-1}$, consistent with other FWHMs found in TIMASSS data for source B (Caux et al. 2011). The $\mathrm{N}_{2} \mathrm{O}$ transition at $226.95 \mathrm{GHz}$ is fitted with a second Gaussian to properly account for the contribution of a nearby methylformate $\left(\mathrm{CH}_{3} \mathrm{OCHO}\right)$ transition. From the fits a rotational temperature diagram is created, shown in Fig. C.2. The diagram gives $T_{\mathrm{ex}}=68 \mathrm{~K}$ and $N=1.7 \times 10^{16} \mathrm{~cm}^{-2}$, using a source size of $1^{\prime \prime} .6$ (see text). Variations in source size will change the excitation temperature and column density slightly.

\section{Appendix D: Upper limit column densities of $\mathrm{NH}_{2} \mathrm{OH}$ and $\mathrm{CH}_{3} \mathrm{NH}_{2}$}

Upper limit column densities of $\mathrm{NH}_{2} \mathrm{OH}$ and $\mathrm{CH}_{3} \mathrm{NH}_{2}$ have been determined for excitation temperatures between 10 and $300 \mathrm{~K}$. These are plotted in Figures D.1 and D.2. The upper limit column densities of $\mathrm{NH}_{2} \mathrm{OH}$ are determined on the three transitions: $7_{0} \rightarrow 6_{0}, 7_{1} \rightarrow 6_{1}, 7_{2} \rightarrow 6_{2}$ transitions at 352522,352730 , and $352485 \mathrm{MHz}$, respectively. These transitions are modelled with a $3 \sigma$ line intensity of 27,21 , and $27 \mathrm{mJy} \mathrm{km} \mathrm{s}^{-1}$, respectively. The

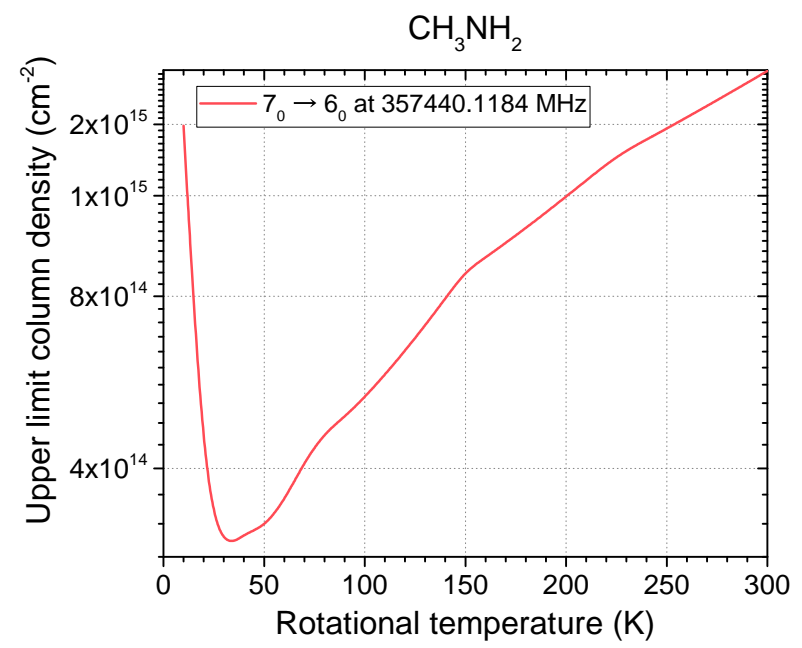

Fig. D.1. Upper limit column density for the strongest $\mathrm{CH}_{3} \mathrm{NH}_{2}$ transition as function of $T_{\mathrm{ex}}$. A $3 \sigma$ value of $23 \mathrm{mJy} \mathrm{km} \mathrm{s}^{-1}$ is used.

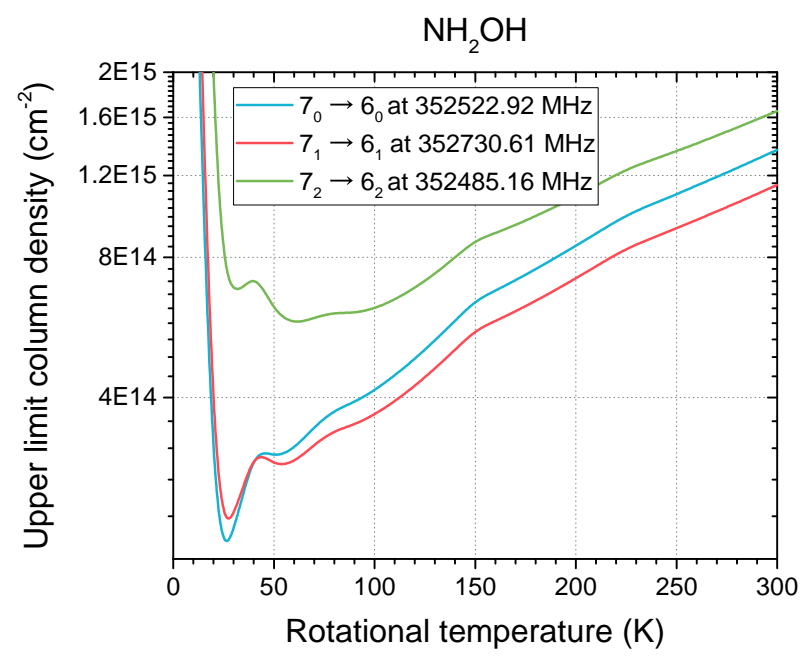

Fig. D.2. Upper limit column densities for the three strongest $\mathrm{NH}_{2} \mathrm{OH}$ transitions as function of $T_{\mathrm{ex}} \cdot 3 \sigma$ values of 27,21 , and $27 \mathrm{mJy} \mathrm{km} \mathrm{s}^{-1}$ are used for the respective lines.

upper limit column densities of $\mathrm{CH}_{3} \mathrm{NH}_{2}$ are determined on the $6_{5} \rightarrow 5_{0}$ transition at $357440 \mathrm{MHz}$ for a $3 \sigma$ line intensity of $23 \mathrm{mJy} \mathrm{km} \mathrm{s}^{-1}$. 


\section{Appendix E: Comparison of $\mathrm{NH}_{2} \mathrm{OH}$ upper limits}

Table E.1. Upper limit abundance ratios for hydroxylamine in IRAS16293-2422.

\begin{tabular}{lcll}
\hline \hline Source & $\mathrm{NH}_{2} \mathrm{OH} / \mathrm{NO}$ & $\mathrm{NH}_{2} \mathrm{OH} / \mathrm{H}_{2}$ & Reference \\
\hline IRAS16293-2422B & $\leq 0.025$ & $\leq 3.1 \times 10^{-11}$ & This work \\
\hline Orion KL & - & $\leq 3 \times 10^{-11}$ & Pulliam et al. (2012) \\
Orion S & - & $\leq 9 \times 10^{-11}$ & Pulliam et al. (2012) \\
IRC+10216 & - & $\leq 3 \times 10^{-9}$ & Pulliam et al. (2012) \\
Sgr B2(OH) & - & $\leq 3 \times 10^{-11}$ & Pulliam et al. (2012) \\
Sgr B2(N) & - & $\leq 8 \times 10^{-12}$ & Pulliam et al. (2012) \\
W51M & - & $\leq 4 \times 10^{-11}$ & Pulliam et al. (2012) \\
W3IRS5 & - & $\leq 3 \times 10^{-11}$ & Pulliam et al. (2012) \\
L1157B1 & - & $\leq 1.4 \times 10^{-8}$ & McGuire et al. (2015) \\
L1157B2 & - & $\leq 1.5 \times 10^{-8}$ & McGuire et al. (2015) \\
\hline Dark cloud model & - & $7 \times 10^{-9}$ & Fedoseev et al. (2012) \\
Hot core model & $7.3-110 \times 10^{-5}$ & $1.6-17 \times 10^{-10}$ & Garrod (2013) \\
\hline
\end{tabular}

Notes. ${ }^{(a)}$ Abundance ranges taken from the $\mathrm{F}($ ast), M(edium), and S(low) warm-up models. 